\title{
$\alpha$-fetoprotein-producing gastric carcinoma: A case report of a rare subtype and literature review
}

\author{
NINGBO SUN ${ }^{1}$, QING SUN ${ }^{2}$, QUN LIU ${ }^{2}$, TIANXIAO ZHANG ${ }^{1}$, \\ QIANG ZHU ${ }^{2}$, WEI WANG ${ }^{2}, \mathrm{MING} \mathrm{CAO}^{2}$ and QI ZANG ${ }^{2}$ \\ ${ }^{1}$ Division of Surgery, Graduate Department, Weifang Medical College, Weifang, Shandong 261031; \\ ${ }^{2}$ Department of Thoracic Surgery, Qianfoshan Hospital, Shandong University, Jinan, Shandong 250014, P.R China
}

Received February 1, 2015; Accepted February 19, 2016

DOI: $10.3892 / \mathrm{ol} .2016 .4372$

\begin{abstract}
AFP)-producing gastric carcinoma is a rare type of gastric cancer, and the characteristics have not yet been fully elucidated. The present study reports the case of a patient with this type of gastric cancer. A 66-year-old male was referred to the Department of Gastrointestinal Surgery, Qianfoshan Hospital, Shandong University (Jinan, China) with a 20-day history of retrosternal pain. A computed tomography (CT) scan revealed a thickening of the wall of the cardia and massive lymph node swelling in the region of the lesser curvature of the stomach. A laboratory investigation revealed that the serum AFP levels of the patient were elevated to $46.49 \mathrm{ng} / \mathrm{ml}$ (normal level, $<12.00 \mathrm{ng} / \mathrm{ml}$ ), and the serum carcinoembryonic antigen (CEA) levels were $382.22 \mathrm{ng} / \mathrm{ml}$ (normal range, $<5.00 \mathrm{ng} / \mathrm{ml}$ ). An endoscopy revealed an elevated tumor and AFP-producing gastric cancer was diagnosed. As the tumor was surgically unresectable, the patient received systemic adjuvant chemotherapy [consisting of 1 cycle of oxaliplatin (150 mg; day 1)-fluorouracil(1.0 g; days 2-6)-calcium folinate (0.3 g; days 2-6), 4 cycles of paclitaxel ( $80 \mathrm{mg}$; day 1 and 8 , repeated day 21) and capecitabine $\left(1,000 \mathrm{~g} / \mathrm{m}^{2}\right.$, twice daily; days 1-14, repeated day 21), and 2 cycles of oxaliplatin $\left(130 \mathrm{mg} / \mathrm{m}^{2}\right.$; day 1 , repeated day 21$)$ and $\mathrm{S}-1$ (100 mg/d; day 1- day 14; repeated day 21)]. During the chemotherapy intermission, the patient experienced partial remission; the serum AFP levels remained between 44.5 and $32.7 \mathrm{ng} / \mathrm{ml}$, and serum CEA levels decreased to a normal level. The CT scan revealed that the enlarged lymph nodes of the patient had decreased in size. During the preoperative examinations, an abdominal CT scan revealed no metastasis to the liver. A radical gastrectomy was performed on October 20, 2014. Additionally, the tumor did
\end{abstract}

Correspondence to: Professor Qi Zang, Department of Thoracic Surgery, Qianfoshan Hospital, Shandong University, 16766 Jingshi Road, Jinan, Shandong 250014, P.R. China

E-mail: qzang2005@sina.com

Key words: $\alpha$-fetoprotein, $\alpha$-fetoprotein-producing gastrical carcinoma, non-hepatoid adenocarcinoma of the stomach, hepatoid adenocarcinoma of the stomach, gastrectomy not demonstrate the diffusion of AFP. The histopathological examination revealed a poorly differentiated adenocarcinoma, with local and neuroendocrine differentiation and no hepatoid features. According to these histopathological findings, the tumor was diagnosed as AFP-producing non-hepatoid adenocarcinoma of the stomach. The patient was treated with systemic immunity-enhancing therapy and has been free of recurrence for 2 months. The present study describes a rare case of AFP-producing non-hepatoid adenocarcinoma of the stomach, with a review of the literature and an investigation of the clinical features.

\section{Introduction}

$\alpha$-fetoprotein (AFP) is an oncofetal glycoprotein that is mainly produced by the yolk sac and liver during fetal development, and to a lesser extent, in the fetal gastrointestinal tract $(1,2)$. The greatest serum AFP levels are observed between 12-15 weeks after birth, which decrease to normal adult levels subsequent to approximately one year $(3,4)$. AFP is detected in the serum of adults with hepatocellular carcinoma, yolk sac tumors and noncancerous liver disease (2-6). Rising AFP levels may also be detected in the malignant tumors of various organs, including the stomach, lung, pancreas, colon, bladder and ovary (7-13). The stomach is one of the most common tumor locations (10). AFP-producing gastric cancer (AFP-GC) was first reported in 1970 by Bourreille (14). The incidence of AFP-GC in all gastric carcinoma ranges between 1.3-15.0\% (15-19). Nagai et al proposed that the defining diagnosis of AFP-GC may be based on the recognition of characteristic histological features (20). AFP-GC may be divided into two subtypes, consisting of AFP-producing non-hepatoid adenocarcinoma and hepatoid adenocarcinoma. AFP-GC is usually diagnosed in the advanced stages of disease and demonstrates a poor prognosis (20-22). In patients exhibiting serum AFP levels of $>300 \mathrm{ng} / \mathrm{ml}$, the 1-, 3-, and 5-year survival rates are 15.4, $7.7 \%$, and $0 \%$, respectively. By contrast, in patients exhibiting serum AFP levels of 20-300 ng/ml, the 1-, 3-, 5- and 10-year survival rates are 46.7, 28.9, 17.8 and $13.3 \%$, respectively (23). Liver metastasis is considered the major independent prognostic factor for AFP-GC patients (24). As AFP-GCs are aggressive tumors, radical resection is the standard treatment, whereas palliative resection is reserved for patients exhibiting 


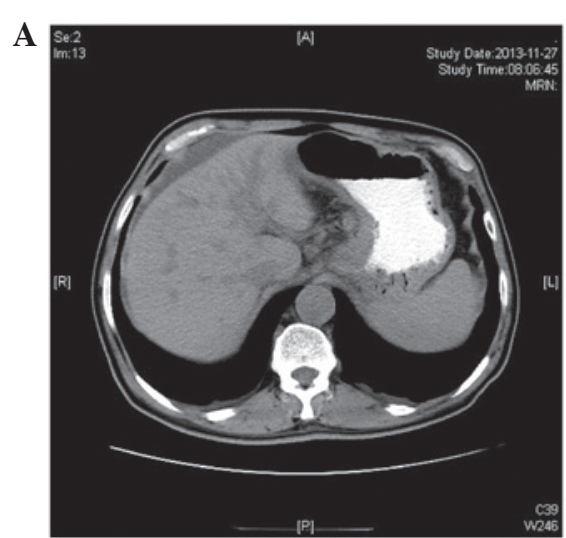

D

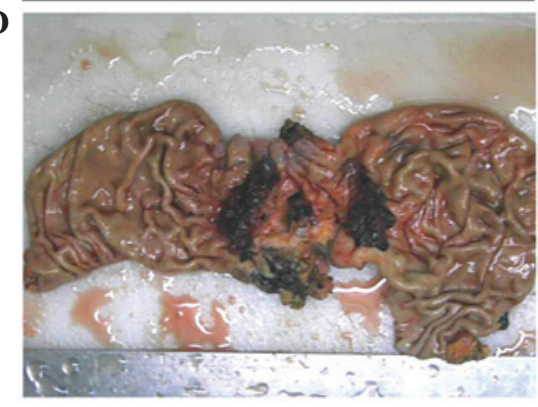

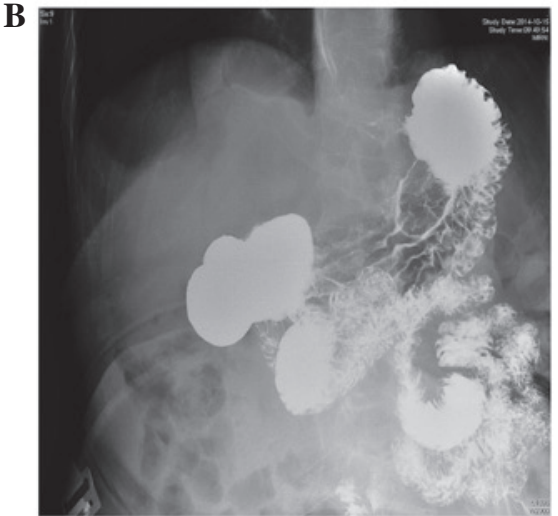

$\mathbf{E}$

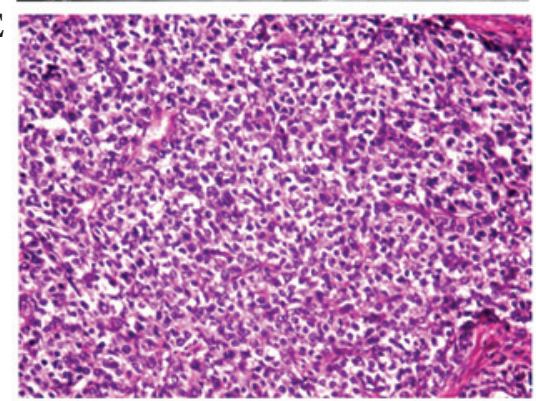

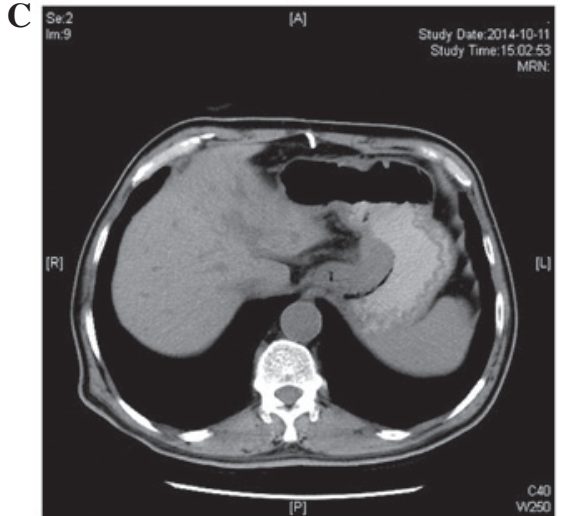

F

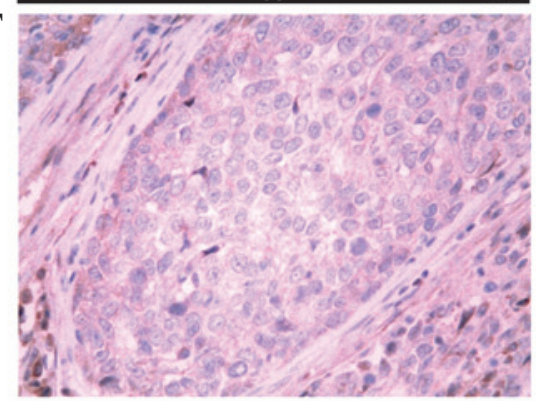

Figure 1. (A) A CT scan revealed a thickening of the cardia wall and massive lymph node swelling in the lesser curvature of the stomach and the head of the pancreas. (B) Upper gastrointestinal radiological studies revealed an irregular structure, a filling defect and wall stiffness at the cardia. (C) A CT scan revealed that the enlarged lymph nodes had decreased in size. (D) The surgically resected specimen revealed an elevated tumor (maximal diameter, $4.0 \mathrm{~cm}$ ) at the cardia, which possessed surface erosion, located between the lesser curvature and the posterior-wall. (E) Microscopically, the tumor was a poorly differentiated adenocarcinoma, and possessed no hepatoid features (H\&E stain; magnification, x100). (F) Immunohistochemistry revealed that the tumor was diffusely negative for $\alpha$-fetoprotein expression (H\&E stain; magnification, x200). CT, computed tomography; H\&E, hematoxylin and eosin.

distant metastasis. Furthermore, adjuvant chemotherapy may be administered to improve the surgical outcomes (25). The present study describes the rare case of a AFP-producing non-hepatoid adenocarcinoma of the stomach, with a review of the literature. Written informed consent was obtained from the patient.

\section{Case report}

A 66-year-old man presented to a local doctor with a 20-day history of retrosternal pain. A radiographic examination of the upper gastrointestinal tract revealed a gastric mass, which was suspected to be gastric cancer. The patient was referred to the Department of Gastrointestinal Surgery, Qianfoshan Hospital, Shandong University (Jinan, China) for additional examination and treatment. A laboratory investigation revealed that the serum AFP levels of the patient were elevated to $46.49 \mathrm{ng} / \mathrm{ml}$ (normal range, $<12.00 \mathrm{ng} / \mathrm{ml}$ ), and the serum carcinoembryonic antigen (CEA) levels were $382.22 \mathrm{ng} / \mathrm{ml}$ (normal range, $<5.00 \mathrm{ng} / \mathrm{ml}$ ). The results of other laboratory tests, including liver function tests, were all within normal limits. A computed tomography (CT) scan revealed a thickening of the wall of the cardia and massive lymph node swelling in the lesser curvature of the stomach and head of the pancreas (Fig. 1A). However, no metastasis was observed. Endoscopy revealed a tumor that demonstrated necrosis and hemorrhage in the lesser curvature of the stomach, which extended between the antrum and body of the stomach. Biopsies of the region identified a poorly differentiated adenocarcinoma. AFP-GC was diagnosed. Laparotomy was performed, which indicated that the carcinoma had extended into the lumen of small lymphatic and venular vessels.

The tumor was surgically unresectable, so the patient received systemic adjuvant chemotherapy, consisting of 1 cycle of oxaliplatin $(150 \mathrm{mg}$; day 1$)$-fluorouracil $(1.0 \mathrm{~g}$; days 2-6)-calcium folinate (0.3 g; days 2-6), 4 cycles of paclitaxel (80 mg; day 1 and 8 , repeated day 21) and capecitabine (1,000 g/m ${ }^{2}$, twice daily; days $1-14$, repeated day 21$)$, and 2 cycles of oxaliplatin $\left(130 \mathrm{mg} / \mathrm{m}^{2}\right.$; day 1 , repeated day 21$)$ and S-1 (100 mg/d; day 1- day 14; repeated day 21). These treatments resulted in partial remission; the serum AFP levels remained between 44.5 and $32.7 \mathrm{ng} / \mathrm{ml}$, and the serum CEA decreased to normal levels (normal range, $<5.0 \mathrm{ng} / \mathrm{ml}$ ). Upper gastrointestinal radiological studies revealed an irregular structure, a filling defect and wall stiffness at the cardia (Fig. 1B). The CT scan showed that the enlarged lymph nodes had decreased in size (Fig. 1C), and there was no evidence of ascites or liver metastasis. A radical gastrectomy was performed on 20 October 2014. The surgically resected specimen revealed an elevated tumor (diameter, $4.0 \mathrm{~cm}$ ) with surface erosion at the cardia (Fig. 1D) that was located between the lesser curvature and the posterior-wall.

Microscopically, the tumor was a poorly differentiated adenocarcinoma (Fig. 1E) that invaded the serous layer region, with local and neuroendocrine differentiation and no hepatoid features. Immunohistochemistry revealed that the tumor did not demonstrate the diffusion of AFP (Fig. 1F). Specific staining for CEA was focally demonstrated in the poorly differentiated adenocarcinomatous region. Three lymph nodes on the lesser curvature and one lymph node on 
the greater curvature demonstrated massive swelling. The prominent intravascular proliferation of non-hepatoid tumor cells, which occasionally form tumor thrombi, was frequently observed. These immunohistochemical findings combined with the previously described features supported the diagnosis of AFP-producing non-hepatoid adenocarcinoma of the stomach. The tumor was diagnosed as stage IIIB (T3N2M0), according to the American Joint Committee on Cancer guidelines (26).

Postoperatively, the serum AFP levels decreased to $18.58 \mathrm{ng} / \mathrm{ml}$ within 2 weeks and the serum AFP levels reached $3.90 \mathrm{ng} / \mathrm{ml} 1$ month subsequent to the surgery. The patient was treated with systemic immunity-enhancing therapy and has been free of recurrence for 2 months.

\section{Discussion}

AFP is an oncofetal glycoprotein mainly produced by the yolk sac and liver during fetal development and, to a lesser extent, in the fetal gastrointestinal tract $(1,2)$. The highest serum levels appear between 12-15 weeks of gestation, and decrease to normal adult levels approximately one year later $(3,4)$. AFP is frequently detected in the serum of adults that have hepatocellular carcinoma, yolk sac tumors and noncancerous liver disease (2-6). Elevated levels of AFP have been detected in the malignant tumors of various organs, including the stomach, lung, pancreas, colon, bladder and ovary (7-13). The stomach is one of the most common locations of these tumors (10). AFP-GC was first reported in 1970 by Bourreille (14). The incidence of AFP-GC in all gastric carcinoma ranges between 1.3-15.0\% (15-19).

Numerous studies have described the histological features of AFP-GC (20,27-29). In 1981, Kodama et al described two histological types of AFP-GC based on immunohistochemical staining, consisting of a medullary type characterized by polygonal cells arranged in solid nests or sheets, and a well-differentiated papillary or tubular type, with clear cytoplasm (27). Ishikura et al proposed the term 'hepatoid adenocarcinoma of the stomach' for primary gastric carcinomas that were characterized by hepatoid differentiation and the production of large amounts of AFP $(28,29)$. To discriminate between non-hepatoid adenocarcinoma and hepatoid adenocarcinoma of the stomach, the measurement of AFP isoforms is also useful, and hepatoid adenocarcinoma of the stomach demonstrates a liver-type binding pattern with the lectin concanavalin A (29). Nagai et al proposed a novel definition, that the diagnosis of AFP-GC may be based on characteristic histological features (20).

AFP-GC may be divided into two subtypes, AFP-producing non-hepatoid adenocarcinoma and hepatoid adenocarcinoma. In the present study, the tumor differed from a hepatocellular carcinoma in histological and morphological characteristics, which led to the diagnosis of an AFP-producing non-hepatoid adenocarcinoma of the stomach. The number of studies reporting this type of tumor at present is fairly small. AFP-GC is usually diagnosed in the advanced stages of disease (20-22). The prognosis of AFP-GC is closely associated with the tumor stage $(20,30)$. Other factors have also been reported as important for predicting the prognosis of patients with AFP-GC (31), including the depth of invasion, degree of lymph node metastasis and AFP expression, and the expression of p21 (32). Previously, factors including increased mitosis, cell movement, proliferative activity, tumor progression, hepatocyte and receptor growth factor, c-Met, vascular endothelial growth factor (VEGF) and the isoform VEGF-C expression were identified as being associated with AFP-GC, and as poor prognostic factors of cancer (33-35). Previously, Dhar et al proposed a novel theory that the poor prognosis of AFP-GC may be associated with the presence of P-glycoprotein (36). Chang et al reported that, even if no metastasis is present preoperatively, liver metastasis may occur within a year following surgery, and that the close observation and long-term follow-up of patients is required (27). In addition, AFP-producing tumors were indicated to demonstrate an increased likelihood of expressing chemoresistance-associated proteins. Hirashima et al (37) proposed that AFP-GC is sensitive to cisplatin, but resistant to fluoropyrimidine prodrugs such as capecitabine, which require conversion into 5-fluorouracil by thymidine phosphorylase (38). Due to the poor prognosis of AFP-GC, accurate diagnosis is important. Clinicians may be required to consider more aggressive treatment options for patients with a good performance status, and recommend resections and additional chemotherapy.

\section{References}

1. Gitlin D, Perricelli A and Gitlin GM: Synthesis of $\alpha$-fetoprotein by liver, yolk sac, and gastrointestinal tract of the human conceptus. Cancer Res 32: 979-982, 1972.

2. Babalı A, Cakal E, Purnak T, Bıyıkoğlu I, Cakal B, Yüksel O and Köklü S: Serum $\alpha$-fetoprotein levels in liver steatosis. Hepatol Int 3: 551-555, 2009.

3. Mizejewski GJ: Levels of alpha-fetoprotein during pregnancy and early infancy in normal and disease states. Obstet Gynecol Surv 58: 804-826, 2003

4. Breborowicz J, Mackiewicz A and Breborowicz D: Microheterogeneity of alpha-fetoprotein in patient serum as demonstrated by lectin affino-electrophoresis. Scand J Immunol 14: 15-20, 1981.

5. Ezaki T, Yukaya H, Ogawa Y, Chang YC and Nagasue N: Elevation of alpha-fetoprotein level without evidence of recurrence after hepatectomy for hepatocellular carcinoma. Cancer 61: 1880-1883, 1988.

6. Ganjei P, Nadji M, Albores-Saavedra J, and Morales AR: Histologic markers in primary and metastatic tumors of the liver. Cancer 62: 1994-1998, 1988.

7. Yamagata T, Yamagata Y, Nakanishi M, Matsunaga K, Minakata $\mathrm{Y}$ and Ichinose M: A case of primary lung cancer producing alpha-fetoprotein. Can Respir J 11: 504-506, 2004.

8. Hamanaka W, Yoneda S, Shirakusa T, et al: Alpha-fetoprotein(AFP)-producing adrenocortical carcinoma-long survival with various therapeutic strategies including a lung resection: Report of a case. Surg Today 38: 275-278, 2008.

9. Matsueda K, Yamamoto H, Yoshida Y, and Notohara K: Hepatoid carcinoma of the pancreas producing protein induced by vitamin $\mathrm{K}$ absence or antagonist II (PIVKA-II) and alpha-fetoprotein (AFP). J Gastroenterol 41: 1011-1019, 2006.

10. Kinjo T, Taniguchi H, Kushima R, Sekine S, Oda I, Saka M, Gotoda T, Kinjo F, Fujita J and Shimoda T: Histologic and immunohistochemical analyses of $\alpha$-fetoprotein-producing cancer of the stomach. Am J Surg Pathol 36: 56-65, 2012.

11. Cappetta A, Bergamo F, Mescoli C, Lonardi S, Rugge M and Zagonel V: Hepatoid adenocarcinoma of the colon: What should we target? Pathol Oncol Res 18: 93-96, 2012.

12. Kawamura N, Hatano K, Kakuta Y, Takada T, Hara T and Yamaguchi S: A case of hepatoid adenocarcinoma of the urinary bladder. Hinyokika Kiyo 55: 619-622, 2009 (In Japanese).

13. Isonishi S, Ogura A, Kiyokawa T, Suzuki M, Kunito S, Hirama M, Tachibana T, Ochiai K and Tanaka T: Alpha-fetoprotein (AFP)-producing ovarian tumor in an elderly woman. Int J Clin Oncol 14: 70-73, 2009. 
14. Bourreille J, Metayer P, Sauger F, Matray F and Fondimare A Existence of alpha feto protein during gastric-origin secondary cancer of the liver. Presse Med 78: 1277-1278, 1970 (In French).

15. Mehlman DJ, Bulkley BH and Wiernik PH: Serum alpha-1-fetoglobulin with gastric and prostatic carcinomas. N Engl J Med 285: 1060-1061, 1971.

16. Akai $\mathrm{S}$ and Kato K: Serum $\alpha$-fetoprotein-positive stomach cancer. Gann Monogr Cancer Res 14: 149-154, 1973.

17. Takahashi Y, Mai M, Ogino T, Ueda H, Sawaguchi K and Ueno M: Clinicopathological study of AFP producing gastric cancer - significance of AFP in gastric cancer. Nihon Geka Gakkai Zasshi 88: 696-700, 1987 (In Japanese).

18. Yonemura Y, Hashimoto T, Sawa T, Shima Y, Kamata T, Nishimura G, Sugiyama K, Koyasaki N, Fujimura T, Tani T et al: The significance of measurement of serum CEA, AFP and hCG in gastric cancer patients. J Jpn Soc Clin Surg 48: 174-179, 1987 (In Japanese).

19. Nishio Y, Urakawa T, Nakamoto M, Yamaguchi T, Tanaka H, Idei H, Noshi T, Iso A, Uematsu K, Iyoroi A and Setoh K: Study of nine cases of $\alpha$-fetoprotein (AFP) producing gastric cancer J Jpn Soc Clin Surg 50: 1176-80, 1989 (In Japanese).

20. Nagai E, Ueyama T, Yao T and Tsuneyoshi M: Hepatoid adenocarcinoma of the stomach. A clinicopathologic and immunohistochemical analysis. Cancer 72: 1827-1835, 1993.

21. Kono K, Amemiya H, Sekikawa T, Iizuka H, Takahashi A, Fujii H and Matsumoto Y: Clinicopathologic features of gastric cancers producing alpha-fetoprotein. Dig Surg 19: 359-365, 2002.

22. Liu X, Cheng Y, Sheng W, Lu H, Xu Y, Long Z, Zhu H and Wang Y: Clinicopathologic features and prognostic factors in alpha-fetoprotein-producing gastric cancers: Analysis of 104 cases. J Surg Oncol 102: 249-255, 2010.

23. Lin HJ, Hsieh YH, Fang WL, Huang KH and Li AF: Clinical manifestations in patients with alpha-fetoprotein-producing gastric cancer. Curr Oncol 21: e394-e399, 2014.

24. Hirajima S, Komatsu S, Ichikawa D, Kubota T, Okamoto K, Shiozaki A, Fujiwara H, Konishi H, Ikoma H and Otsuji E: Liver metastasis is the only independent prognostic factor in AFP-producing gastric cancer. World J Gastroenterol 19: 6055-6061, 2013.

25. Zhang JF, Shi SS, Shao YF and Zhang HZ: Clinicopathological and prognostic features of hepatoid adenocarcinoma of the stomach. Chin Med J 124: 1470-1476, 2011.

26. Sobin LH, Gospodarowicz M and Wittekind C (eds): Stomach. In: UICC International Union Against Cancer. TNM Classification of Malignant Tumours. 7th edition. Wiley-Blackwell, Oxford, pp73-77, 2009.

27. Kodama T, Kameya T, Hirota T, Shimosato Y, Ohkura H, Mukojima T and Kitaoka H: Production of $\alpha$-fetoprotein, normal serum proteins, and human chorionic gonadotropin in stomach cancer: Histologic and immunohistochemical analyses of 35 cases. Cancer 48: 1647-1655, 1981
28. Ishikura H, Fukasawa Y, Ogasawara K, Natori T, Tsukada Y and Aizawa M: An AFP-producing gastric carcinoma with features of hepatic differentiation: A case report. Cancer 56: $840-848,1985$

29. Ishikura H, Kirimoto K, Shamoto M, Miyamoto Y, Yamagiwa $H$, Itoh $\mathrm{T}$ and Aizawa $\mathrm{M}$ : Hepatoid adenocarcinomas of the stomach: An analysis of seven cases. Cancer 58: 119-126, 1986.

30. Adachi Y, Tsuchihashi J, Shiraishi N, Yasuda K, Etoh T and Kitano S: AFP-producing gastric carcinoma: Multivariate analysis of prognostic factors in 270 patients. Oncology 65: 95-101, 2003.

31. Chun H and Kwon SJ: Clinicopathological characteristics of alpha-fetoprotein-producing gastric cancer. J Gastric Cancer 11: 23-30, 2011.

32. Liu X, Yu H, Cai H and Wang Y: Expression of CD24, p21, p53, and c-myc in alpha-fetoprotein-producing gastric cancer: Correlation with clinicopathologic characteristics and survival. J Surg Oncol 109: 859-864, 2014.

33. Koide N, Nishio A, Igarashi J, Kajikawa S, Adachi W and Amano J: Alpha-fetoprotein-producing gastric cancer: Histochemical analysis of cell proliferation, apoptosis, and angiogenesis. Am J Gastroenterol 94: 1658-1663, 1999.

34. Amemiya H, Kono K, Mori Y, Takahashi A, Ichihara F, Iizuka $\mathrm{H}$, Sekikawa $\mathrm{T}$ and Matsumoto $\mathrm{Y}$ : High frequency of c-Met expression in gastric cancers producing alpha- fetoprotein. Oncology 59: 145-151, 2000.

35. Kamei S, Kono K, Amemiya H, Takahashi A, Sugai H, Ichihara F, Fujii $\mathrm{H}$ and Matsumoto Y: Evaluation of VEGF and VEGF-C expression in gastric cancer cells producing alpha-fetoprotein. J Gastroenterol 38: 540-547, 2003

36. Dhar DK, Nagasue N, Yoshimura H, Tachibana M, Tahara $\mathrm{H}$, Matsuura $\mathrm{H}$, Abe $\mathrm{S}$, Chang YC and Nakamura T: Overexpression of P-glycoprotein in untreated AFP-producing gastric carcinoma. J Surg Oncol 60: 50-54, 1995.

37. Hirashima Y, Kitajima K, Sugi S, Kagawa K, Kumamoto T, Murakami K, Fujioka T and Noguchi T: Successful bi-weekly paclitaxel treatment of an AFP-producing gastric cancer patient with peritoneal dissemination and multiple liver metastasis. Gan To Kagaku Ryoho 33: 517-519, 2006.

38. Kamoshida S, Suzuki M, Sakurai Y, Ochiai M, Kimura F, Kuwao S, Sakamoto K, Sugimoto Y, Fukushima M and Tsutsumi Y: Expression of chemoresistance-related proteins in alpha-fetoprotein-producing adenocarcinoma of the digestive organs. Oncol Rep 16: 721-727, 2006. 